\title{
REPRESENTATION OF THE PHENOMENON "TRUST" IN MEDICAL ADVERTISING DISCOURSE
}

\author{
Nikolay L. Shamne \\ Volgograd State University, Volgograd, Russia \\ Ekaterina V. Shishkina \\ Volgograd State Medical University, Volgograd, Russia
}

\begin{abstract}
The problem of creating institutional trust in modern Russian society is considered on the example of advertising activities of companies that produce and promote drugs on the consumer market. In order to identify techniques that contribute to the effective impact on the recipient - the formation of a trusting attitude towards the advertised product, the commercials shown on Russian television from 2010 to 2020 were analyzed. Using the methods of content analysis, discourse and stylistic analysis, elements of component and distributive analysis, it has been established that professional participants in medical advertising discourse use such techniques as the use of toponyms, lexical units borrowed from military discourse, terms, words with positive or negative connotations, presentation of statistical data, construction of a first-person statement, rhetorical questions. It was found that the mention of the country of origin of the drug, which is authoritative for the Russian consumer, has a positive effect on the confidence of patients in this drug; military vocabulary evokes associations with speed, accuracy, direction, strength and testifies to the effectiveness of the drug; medical, chemical, biological terms, statistical data objectify the transmitted information; rhetorical questions, self-narrative and others contribute to the establishment of close contact with the consumer.

Key words: medical discourse, advertising discourse, trust, linguistic and stylistic technique, impact, impact effectiveness.

Citation. Shamne N.L., Shishkina E.V. Representation of the Phenomenon "Trust" in Medical Advertising Discourse. Vestnik Volgogradskogo gosudarstvennogo universiteta. Seriya 2. Yazykoznanie [Science Journal of Volgograd State University. Linguistics], 2021, vol. 20, no. 5, pp. 167-176. (in Russian). DOI: https://doi.org/ 10.15688/jvolsu2.2021.5.13
\end{abstract}

\section{РЕПРЕЗЕНТАЦИЯ ДОВЕРИЯ В МЕДИЦИНСКОМ РЕКЛАМНОМ ДИСКУРСЕ}

\section{Николай Леонидович Шамне}

Волгоградский государственный университет, г. Волгоград, Россия

\section{Екатерина Викторовна Шишкина}

Волгоградский государственный медицинский университет, г. Волгоград, Россия

Аннотация. Проблема создания институционального доверия в современном российском социуме рассмотрена на примере рекламной деятельности компаний, производящих и продвигающих на потребительском рынке лекарственные препараты. С целью выявить приемы, способствующие эффективному воздействию на получателя - формированию доверительного отношения к рекламируемому продукту, проанализированы рекламные ролики, демонстрировавшиеся по российскому телевидению с 2010 по 2020 год. 
С применением методов контент-анализа, дискурсивного анализа, а также элементов компонентного, дистрибутивного и стилистического анализа определено, что профессиональными участниками медицинского рекламного дискурса для установления доверия со стороны клиентов дискурса используются такие приемы, как употребление топонимов, лексических единиц, заимствованных из военного дискурса, терминов, слов с положительной или отрицательной коннотацией, приведение статистических данных, построение высказывания от первого лица, риторические вопросы. Выявлено, что упоминание страны-производителя препарата, авторитетной для российского потребителя, положительно влияет на доверие пациентов к лекарственному средству; военная лексика вызывает ассоциации со скоростью, точностью, направленностью, силой и свидетельствует о действенности медпрепарата; медицинские, химические, биологические термины, статистические данные объективируют транслируемую информацию; риторические вопросы, я-нарратив и другие способствуют возникновению близкого контакта с потребителем.

Ключевые слова: медицинский дискурс, рекламный дискурс, доверие, лингвостилистический прием, воздействие, эффективность воздействия.

Цитирование. Шамне Н. Л., Шишкина Е. В. Репрезентация доверия в медицинском рекламном дискурсе // Вестник Волгоградского государственного университета. Серия 2, Языкознание. - 2021. - Т. 20, № 5. C. 167-176. - DOI: https://doi.org/10.15688/jvolsu2.2021.5.13

\section{Введение}

Актуализация дихотомии «доверие - недоверие» в российском социуме обусловлена как общемировыми тенденциями развития информационного общества, так и локальными социальными трансформациями последних десятилетий. В этой связи С. Купрейченко характеризует сформировавшийся в российском обществе к середине 1990-х гг. общественно-психологический феномен, получивший наименование «дефицит доверия». Он является негативным последствием радикальных политических и экономических преобразований, которые происходили в нашей стране в начале 1990-х гг. и привели к становлению континуума социальной неопределенности. Дефицит доверия остро ощущался в тот исторический период в большинстве сфер жизнедеятельности людей, особенно в экономике, политике и социальной сфере [Купрейченко, 2008, с. 7]. Проблема снижения уровня доверия в обществе остается актуальной и сегодня (согласно докладу о состоянии гражданского общества в Российской Федерации за 2018 г. всего 39,5 \% граждан доверяют организациям, в деятельности которых они могут лично убедиться).

В связи с этим в последние годы усиливается научный интерес к исследованию институционального доверия в разных аспектах (см., например: [Данкин, 2013; Изотова, 2009; Коулман, 2001; Левада, 2001; Таханова, Цыренова, 2013; Thom et al., 2002]), что отразилось в толкованиях данного понятия. Так, социальное доверие определяется как институ- ализированная форма деятельного признания достоинства и индивидуальности всякого другого (не только родственника, единоверца, друга, соседа), осуществляемого в бессрочный символический кредит с негарантированной (государством, бюрократическими структурами, правительственными комиссиями) возможностью погашения этими другими или третьими лицами в неопределенном будущем. [Мальцева и др., 2017, с. 40-41]. Ф. Фукуяма рассматривает доверие как релевантный ресурс социального капитала, необходимый для объединения людей в коллектив, их сотрудничества для достижения общих целей [Фукуяма, 2004, с. 56]. Многие ученые приравнивают доверие к отношению (см.: [Frederiksen, 2014, Larzelere, Huston, 1980; Levi, Stoker, 2000; Lewis, Weigert, 1985; и др.]), что, на наш взгляд, является одним из самых естественных подходов к изучению этого феномена, поскольку доверие не возникает безотносительно и всегда неизменно коррелирует с отношением одного индивидуума к другому.

В научной литературе представлены классификации доверия: выделяются личностное, межличностное, институциональное, общее, а также вертикальное, горизонтальное, локальное, системное [Дементьев, 2011; Ляско, 2004; Трапкова, 2004; Шапошникова, 2008; Stolle, 2002]. Межличностное, межиндивидуальное, персонифицированное, или горизонтальное доверие, характеризует взаимоотношения между партнерами. Институциональное доверие отражает отношение граждан к социальным институтам и их представителям: си- 
стемам образования и здравоохранения, институту церкви, брака и т. д., возникающее под воздействием социокультурных, политических и экономических процессов.

Исследователи неизменно противопоставляют доверие и недоверие, отмечая, что первое оказывает позитивное воздействие на жизнедеятельность субъекта, а второе, напротив, негативное. Однако невозможно полностью согласиться с такой трактовкой, поскольку доверие и недоверие выполняют ряд схожих функций: отражают социально-психологическое окружение индивидуума, регулируют связи с окружающим миром и др. Не только недоверие, но и некоторые формы и виды доверия выполняют деструктивные функции при формировании сознания и поведения субъекта, что приводит к негативным последствиям.

Несмотря на имеющиеся достижения в научном осмыслении институционального доверия, в области медицинского дискурса проблемы его возникновения и проявления остаются неконцептуализированными. Здоровье это базовая человеческая ценность, а медицинские услуги всегда сопряжены для пациента не только с надеждами на улучшения качества жизни, выздоровление, но и с определенными рисками для здоровья. По данным опроса агентства социологических исследований и коммуникативных решений Фонда общественного мнения (далее - ФОМ; https:// fom-gk.ru/), при возникновении симптомов заболевания лишь $33 \%$ россиян незамедлительно обращается к врачу, а $63 \%$ предпочитают лечиться самостоятельно, $42 \%$ респондентов из обратившихся к врачам не в полной мере доверяют полученным предписаниям. Анкетирование, проведенное ФОМ среди медицинского персонала показало, что 37 \% врачей не нуждаются в доверии со стороны пациента. Однако подавляющее большинство опрошенных (63\%) уверены, что оно необходимо для установления взаимодействия с пациентом и положительного исхода лечения.

В сложившихся условиях отмечается увеличение поисковых запросов о здоровье (возможностях лечения, симптомах болезней, профилактике) в глобальной сети: в 2005 г. информацию, относящуюся к здоровью, искали 117 миллионов пользователей; в 2006 г. их количество возросло на $16 \%$, а в 2019 г. - пре- высило миллиард (см. статистику поисковых запросов на yandex.ru и google.com). Не менее востребованным источником медицинской информации является реклама лекарственных препаратов. Так, на вопрос «Почему не следует запрещать рекламу безрецептурных лекарственных препаратов?», заданный ФОМ респондентам, были получены следующие ответы: «Это возможность получить информацию о лекарствах», «Сложно, неудобно за любым лекарством идти к врачу», «Иногда такая реклама помогает», «У людей должно быть право выбора», «Лекарства без рецепта безопасны» (https://fom-gk.ru/).

В наших предыдущих публикациях среди факторов, способствующих самодиагностике и самолечению, выделены следующие: низкий уровень квалификации медицинского персонала; увеличение стоимости визита к врачу; свободный доступ к медицинским инструментам для самодиагностики и самолечения; отпуск медикаментов без рецепта; недоверие пациента к лечащему врачу; избыточное количество информации медицинского характера в свободном доступе (см., например: [Шамне, Шишкина, 2017]).

В настоящей статье проблема доверия потребителей к общественным и частными институтам исследуется на примере рекламной деятельности компаний-производителей лекарственных средств и маркетинговых агентств. В частности, выделяются приемы, которые используются для установления доверительного отношения со стороны получателя рекламы лекарственных препаратов.

\section{Материал и методы}

Материалом для анализа послужили 106 рекламных роликов медицинских препаратов, обнаруженные в результате сплошной выборки из видео-рекламы, транслировавшейся на российском телевидении в период с 2010 по 2020 год. Изучаемый материал находится в свободном доступе в сети Интернет. В исследовании применялись контент-анализ, дискурсивный анализ, элементы компонентного, дистрибутивного и стилистического анализа. Учитывается, что реклама, будучи жанром медицинского научно-популярного дискурса, отражает статусное неравноправие его участни- 


\section{МАТЕРИАЛЫ И СООБЩЕНИЯ}

ков, которое определяет выбор ими дискурса приемов, служащих для эффективного воздействия на получателя.

\section{Результаты и обсуждение}

Для установления доверительного отношения со стороны реципиента рекламодатели используют целый ряд приемов: употребление топонимов, лексических единиц военной сферы, медицинской и другой терминологии, просторечий, риторические вопросы, создание я-нарратива, упоминание статистических данных и др. Рассмотрим их подробно.

Результаты эксперимента, проведенного ФОМ, свидетельствуют о том, что более половины респондентов предпочитает иностранные лекарственные препараты отечественным (https://fom.ru/Ekonomika/12729). Следовательно, такие топонимы, как Германия, Чехия и др., вызывают доверие зрителей. Примером может служить реклама сиропа от кашля «Амбробене» (https://www.youtube.com/ watch?v=IuHL1N1zrAU), где колоритный немец с соответствующим акцентом поет: $я$ из Германия прибыть, сироп целебный привозить. Помимо устного упоминания о стране-производителе, на экране крупным шрифтом приведена надпись Господин из Германии (рис. 1). Германия давно известна высоким качеством оказываемых услуг. Эта стра- на с развитым медицинским туризмом: по данным ФОМ, 35\% процентов россиян хотели бы лечиться здесь (https://fom.ru/Ekonomika/ 12729). В рекламном ролике также сообщается о преимуществах данного лекарственного средства перед другими: без консервантов он лечить, он бронхи очищает, мокроту разжижает. При этом на экране появляется надпись Без красителей, загустителей $и$ консервантов.

Очевидно, что для потребителей, которые заботятся о своем здоровье, положительным фактором, вызывающим доверие, является натуральный состав лекарственных препаратов и отсутствие вредных вспомогательных компонентов. Поэтому лексемы краситель, загуститель, консервант обладают негативной коннотацией в сознании клиентов медицинского дискурса.

Производители лекарственных средств активно используют в рекламе лексические единицы, характерные для военного дискурса: ликвидировать, блокировать, сопротивление, противоборствующий, оперативное применение, защитные силь, уничтожение:

(1) Эргоферон - борьба с вирусами, снятие воспаления, укрепление иммунитета (https://www. youtube.com/watch?v=uY4Vh4PxzgA);

(2) Арбидол блокирует размножение вирусов и способствует их ликвидации, защищая семью (https://www.youtube.com/watch? $\mathrm{v}=\mathrm{nFyAzM0zYZI).}$

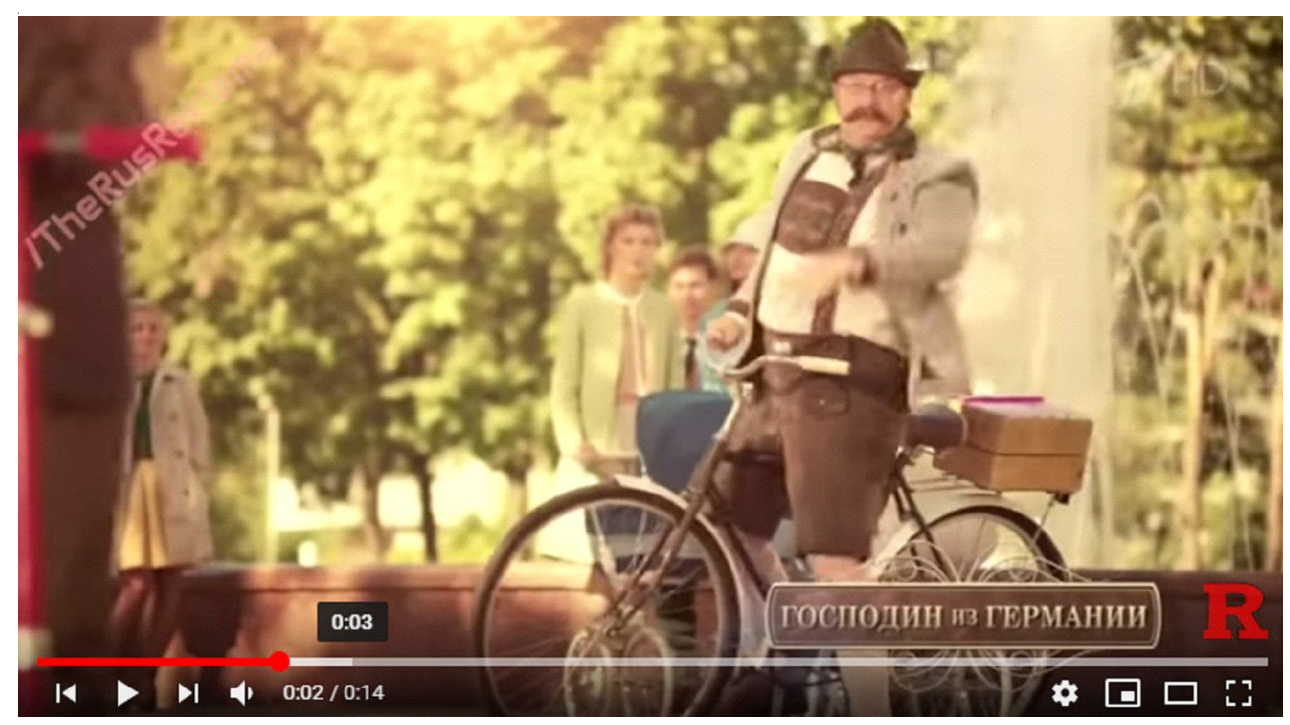

Рис. 1. Фрагмент рекламы лекарственного средства «Амбробене»

Fig. 1. Ambrobene drug advertisement excerpt 
В сознании человека военная сфера ассоциируется с точностью, направленным действием, быстротой реагирования, в связи с этим употребление соответствующих лексических единиц способствует укреплению доверия со стороны потенциальных потребителей лекарственных средств.

В конце каждого ролика, рекламирующего медикаменты, производитель обязательно ссылается на наличие противопоказаний и необходимость проконсультироваться со специалистом (рис. 2), что соответствует пункту 6 статьи 44 Федерального закона №122-Ф3 «О лекарственных средствах».

Среди лексических средств, служащих для репрезентации доверия необходимо отметить терминологические единицы. Реципиентами медицинской научно-популярной информации являются люди, не имеющие специализированного образования, поэтому умеренное использование профессиональной лексики способствует пониманию информации получателем и формированию образа компетентного, дружелюбного и готового помочь отправителя. Например, реклама противовирусного препарата «Кагоцел» сообщает:

(3) Когда вирусы простуды и гриппа атакуют, а лечение опаздывает, тогда на помощь придет «Кагоцел». Он вызывает образование интерферонов с высокой противовирусной активностью (https:// www.youtube.com/watch?v=xbzURoP122c).

Благодаря активной рекламе противовирусных средств, большинство потребителей знают, что интерфероны - это некие вещества, помогающие иммунной системе человека бороться с инфекцией. Однако медицинская дефиниция данного понятия сложнее: «Интерфероны (сокр. IFN) - общее название ряда белков со сходными свойствами, выделяемых клетками организма в ответ на вторжение вируса, некоторые бактериальные вещества и низкомолекулярные химические соединения [Большой словарь медицинских терминов, 2007, c. 407].

Некоторые термины, не вошедшие в речевой обиход населения, сопровождаются в рекламе пояснением. Так, профессиональные участники медицинского дискурса знают, что лизоцим - антибактериальный агент, фермент класса гидролаз, разрушающий клеточные стенки бактерий гидролизом пептидогликана (муреина) [Большой словарь медицинских терминов, 2007, с. 458]. Однако для потребителей доступно объясняются основные функции данного вещества в рекламе препарата «Лизобакт»:

(4) Лизобакт содержит лизоцим, он борется с бактериями, грибами и вирусами (https:// www.youtube.com/watch? $\mathrm{v}=\mathrm{XPEZY3K4au4).}$

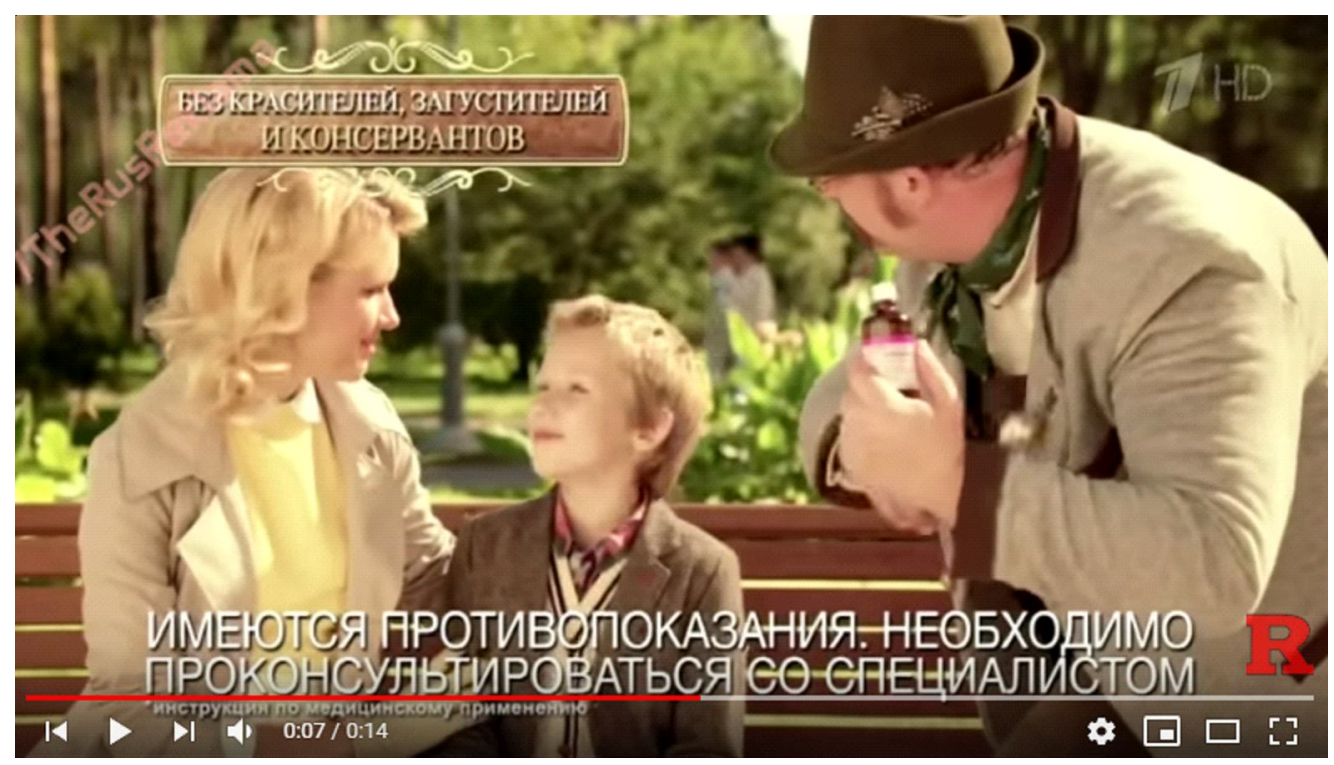

Рис. 2. Фрагмент рекламы лекарственного средства «Амбробене»

Fig. 2. Ambrobene drug advertisement excerpt 


\section{МАТЕРИАЛЫ И СООБЩЕНИЯ}

Термин «фосфолипид», использованный в рекламе препарата «Эссенциале Форте Н», раскрывается в рекламе через описание его воздействия на организм человека, а не его структуры как сложного липида или эфира высших жирных кислот и многоатомных спиртов:

(5) Только Эссенциале Форте Н содержит высокую концентрацию фосфолипидов EPL, которые способствуют регенерации клеток печени и нормализации метаболических процессов (https:// www.youtube.com/watch?v=A__j_kKhhIs).

При этом производители препарата «Фосфоглив» используют медицинскую терминологию только в надписях (рис. 3), а закадровый голос произносит:

(6) Два активных компонента «Фосфоглива» созданы устранять причины повреждения и восстанавливать клетки печени (https://www.youtube. $\mathrm{com} /$ watch? $\mathrm{v}=553$ owdj5z0s).

Отправитель сознательно избегает озвучивания непонятных для клиентов медицинского дискурса терминов «глицирризиновая кислота» и «эссенциальные фосфолипиды».

Убежденность потребителей в действенности того или иного препарата часто основывается на их личном опыте или опыте других потребителей. Именно поэтому производители лекарственных средств приводят в тексте рекламы статистические данные. Так, в рекламе пробиотика «Энтерол» говорится:
(7) Родители более чем в 90 странах знают, что прием антибиотиков надо сопровождать курсом «Энтерола» (https://www.youtube.com/ watch?v=HyNxMlCGtuo).

Завершает ролик дублированная надпись «Пробиотик № 1 в мире» (см. рис. 4).

В рекламе зубной щетки «OralB» видеоряд дублируется высказыванием:

(8) OralB - марка зубных щеток № 1, которую рекомендуют стоматологи во всем мире (https:// www.youtube.com/watch?v=_WPRy6Gjc4U).

Производители противовирусного средства «Анаферон» также используют этот прием и завершают свою рекламу следующим текстом:

(9) Марка № 1 в России в категории «Противовирусное средство» в 2015 году (https://www. youtube.com/watch?v=3c4DoSvHdec).

Статистические данные приводят производители кисломолочного напитка «Имунеле»:

(10) По статистике до $36 \%$ мужчин не надевают зимой кальсоны. Более $50 \%$ женщин считают, что шапка - враг прически. А среднестатистический школьник съедает за зиму до 4 метров сосулек (https://www.youtube.com/watch?v= oicKvZS6ET0).

Для того чтобы вызвать доверие со стороны потребителя, отправитель нивелирует разностатусный характер дискурса и строит высказывание от первого лица (создает я-нарратив):

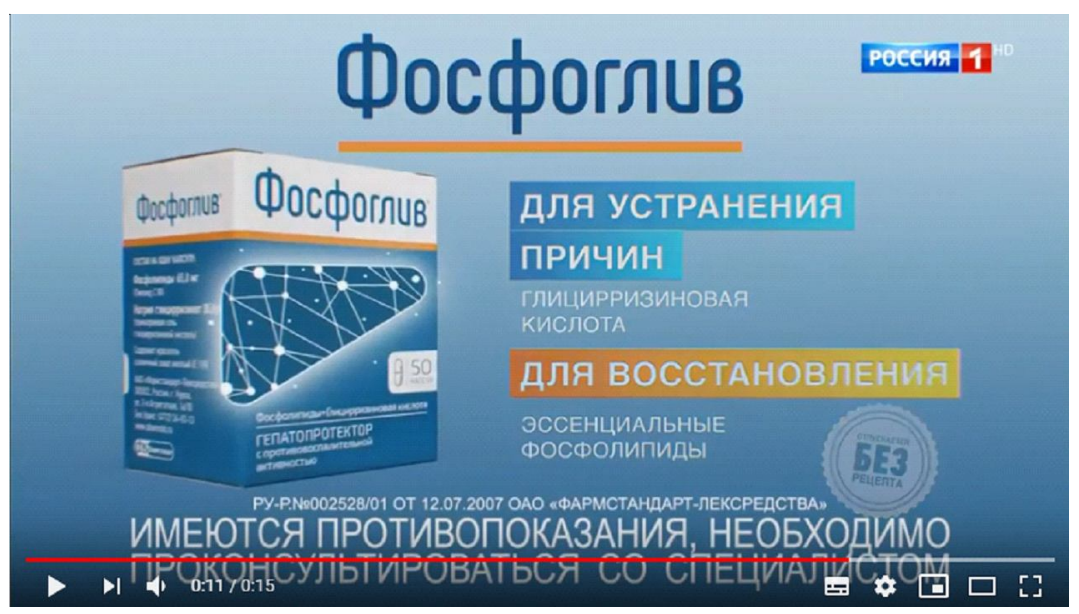

Рис. 3. Фрагмент рекламы лекарственного средства «Фосфоглив»

Fig. 3. Phosphogliv drug advertisement excerpt 


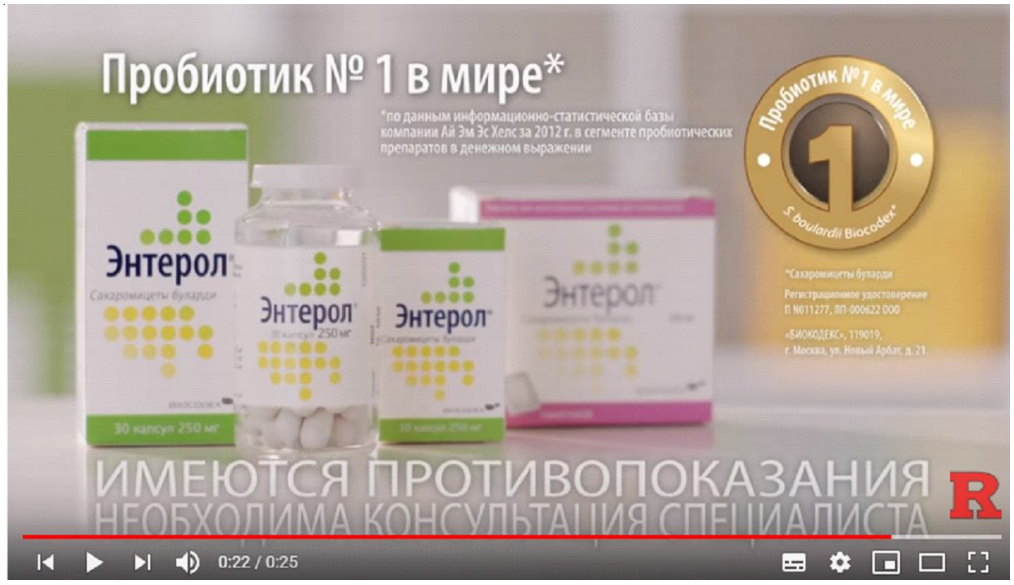

Рис. 4. Фрагмент рекламы лекарственного средства «Энтерол»

Fig. 4. Enterol drug advertisement excerpt

(11) Мы в Colgate считаем, что структура полости рта уникальна. Зубная эмаль - самая твердая ткань в нашем организме. Десять тысяч вкусовых рецепторов обновляются каждые десять дней. Вот почему мы создали зубную пасту ColgateTotal» (https://www.youtube.com/watch?v= fvATh6hlTxM);

(12) «Анаферон детский» создан специально для детей. А для себя я тоже выбираю «Анаферон» (https://www.youtube.com/watch?v=3c4DoSvHdec).

Укреплению доверия к медицинскому препарату способствует участие в рекламных роликах знаменитостей. Так, рекламируя спрей от боли в горле, с экрана убедительно поет известный рэп-исполнитель Тимати:

(13) Сильное средство, даже сильнее цунами. Это тот случай, когда можно доверять рекламе (https://www.youtube.com/watch?v= j7WZO2sDXZE).

Певец заявляет, что сам использует данный медикамент и считает его действенным. Здесь доверие / недоверие переходит с институционального на межличностный уровень: получатель выражает свое отношение не столько к производителю медикамента или самому продукту, сколько к человеку, транслирующему информацию.

Приемом, способствующим укреплению доверия со стороны непрофессиональных участников медицинского дискурса, является риторический вопрос, на который потенциальный потребитель лекарственного средства мог бы дать положительный ответ:
(14) Вздутие живота? Чувствуете себя неловко? Испытываете неудобство? Пытаетесь скрыть симптомы? (https://www.youtube.com/watch?v=XrUl8Cp5QRs).

Далее предлагается решение имеющихся проблем:

(15) Попробуйте «Эспумизан»! «Эспумизан» помогает устранить вздутие, «схлопывая» пузырьки газа в кишечнике, и вы снова чувствуете себя увереHo! (https://www.youtube.com/watch? v=XrUl8Cp5QRs).

В этом тексте наблюдается также использование просторечного глагола схлопывать, что делает понятным для реципиента процесс действия лекарственного средства на организм. Риторические вопросы используются, как правило, при упоминании проблем со здоровьем, говорить о которых пациенты смущаются (дисфункция кишечника, нарушения деятельности мочеполовой системы и пр.):

(16) Беспокоят проблемы с пищеварением? Дискомфорт после еды? Примите «Креон»! В отличие от других препаратов «Креон» содержит сотни уникальных мини-микросфер. Они достигают максимальной активности уже через 15 минут и улучшают пищеварение (https://www.youtube.com/ watch? $\mathrm{v}=\mathrm{T} 5 \mathrm{ZsKV}$ srw5o).

С помощью выявленных в результате исследования приемов рекламодатели презентуют медицинские препараты, информируя потенциального потребителя о лучших качествах своей продукции. Цель таких рекламных роликов - достичь доверительного отношения со стороны реципиента, главного потребителя рекламируемого продукта. 


\section{Выводы}

В результате анализа материала были установлены приемы, позволяющие профессиональным участникам медицинского рекламного дискурса установить доверие со стороны клиентов дискурса: использование топонимов, лексических единиц, заимствованных из военного дискурса, терминов, слов с положительной или отрицательной коннотацией, я-нарратива, риторических вопросов, аргументации, подкрепленной статистическими данными и участием в ней знаменитостей. Упоминание страны-производителя, авторитетной в глазах российского потребителя, положительно влияет на доверие пациентов к данному лекарственному средству; военная лексика вызывает ассоциации со скоростью, точностью, направленностью, силой и свидетельствует о действенности препарата; термины из областей медицины, химии, биологии, а также статистические данные объективируют транслируемую информацию, усиливают аргументацию в пользу того или иного препарата; а риторические вопросы, относящиеся к проблемам со здоровьем, и я-нарратив способствуют установлению близкого контакта с потребителем.

\section{СПИСОК ЛИТЕРАТУРЫ}

Большой словарь медицинских терминов : А-Я, 2007 / сост. В. Д. Федотов. М. : Центрполиграф. $958 \mathrm{c}$.

Данкин Д. М., 2013. Доверие и недоверие в условиях развития гражданского общества / отв. ред. А. Б. Купрейченко, И. В. Мерсиянова. М. : Изд. дом НИУ ВШЭ. 564 c.

Дементьев И. А., 2011. Доверие как индикатор социального капитала // Вестник Поморского университета. Серия: Гуманитарные и социальные науки. № 1. С. 40-45.

Изотова А. В., 2009. Доверие в системе «врач - пациент» // Здоровье - основа человеческого потенциала: проблемы и пуги их решения. Т. 6 , № 1. C. 137-143.

Коулман Дж., 2001. Капитал социальный и человеческий // Общественные науки и современность. № 3. С. 122-139.

Купрейченко А. Б., 2008. Психология доверия и недоверия. М. : Ин-т психологии РАН. 564 с.

Левада Ю. А., 2001. Механизмы и функции общественного доверия // Мониторинг обществен- ного мнения: экономические и социальные перемены. № 3. С. 7-13.

Ляско А. К., 2004. Проблема доверия в социальноэкономической теории. М. : Ин-т экономики PAH. 189 c.

Мальцева А. П., Поляков С.Д., Семикашева И.А., Силакова М.М., Еремина Л.И., 2017. Социальное доверие как новое направление исследований в педагогике // Поволжский педагогический поиск. № 1 (19). С. 38-44.

Таханова О. В., Цыренова Е. Д., 2013. Институг доверия в современной экономике России. Улан-Удэ : Изд-во ВСГУТУ. 180 с.

Трапкова А. В., 2004. Доверие в российском малом и среднем бизнесе // Общественные науки и современность. № 4. С. 36-48.

Федеральный закон №122-Ф3 «О лекарственных средствах». Статья 44. Реклама лекарственных средств. URL: https://legalacts.ru/doc/ federalnyi-zakon-ot-22061998-n-86-fz-o/.

Фукуяма Ф., 2004. Доверие: социальные добродетели и путь к процветанию : пер. с англ. М. : АСТ ; Ермак. 730 c.

Шамне Н. Л., Шишкина Е. В., 2017. Научно-популярные медицинские интернет-издания на немецком языке: структурный и функциональный аспекты // Вестник Волгоградского государственного университета. Серия 2. Языкознание. Т. 16, № 2. C. 143-151. DOI: https:// doi.org/10.15688/jvolsu2.2017.2.15.

Шапошникова В. В., 2008. Институт доверия как нравственная основа социального капитала // Вестник Костромского государственного технологического университета. № 18. C. 16-19.

Frederiksen M. 2014. Relational Trust: Outline of a Bourdieusian Theory of Interpersonal Trust // Journal of Trust Research. № 4 (2). P. 167-192.

Larzelere R. E., Huston T. L., 1980. The Dyadic Trust Scale: Toward Understanding Interpersonal Trust in Close Relationships // Journal of Marriage and the Family. Vol. 42, № 3. P. 595-604.

Levi M., Stoker L. 2000. Political Trust and Trustworthiness // Annual Review of Political Science. Vol. 3. P. 475-507.

Lewis J. D., Weigert A. J., 1985. Trust As a Social Reality // Social Forces. Vol. 63, № 4. P. 967-985.

Thom D. H., Kravitz R. L., Bell R. A., Krupat E., Azari R., 2002. Patient Trust in the Physician: Relationship to Patient Requests // Family Practice. Vol. 19, № 5. P. 476-483.

Stolle D., 2002. Trusting Strangers : The Concept of Generalized Trust in Perspective // Österreichische Zeitschrift für Politikwissenschaft. Bd. 31, № 4. S. 397-412. 


\section{REFERENCES}

Fedotov V.D., ed., 2007. Bolshoy slovar meditsinskikh terminov [Large Dictionary of Medical Terms]. Moscow, Tsentrpoligraf Publ. 958 p.

Dankin D.M., 2013. Doveriye i nedoveriye v usloviyakh razvitiya grazhdanskogo obshchestva [Trust and Mistrust in the Development of Civil Society]. Moscow, Izdatelskiy dom NIU VSHE. $564 \mathrm{p}$.

Dementyev I.A, 2011. Doveriye kak indikator sotsialnogo kapitala [Trust As an Indicator of Social Capital]. Vestnik Pomorskogo universiteta. Seriya: Gumanitarnyye $i$ sotsialnyye nauki [Bulletin of the Pomor University. Series: Humanities and Social Sciences], no. 1, pp. 40-45.

Izotova A.V., 2009. Doveriye v sisteme «vrach - patsiyent» [Trust in the "Doctor - Patient" System]. Zdorovye-osnova chelovecheskogo potentsiala: problemy i puti ikh resheniya [Health is the Basis of Human Potential: Problems and Ways to Solve Them], no. 1,pp. 137-143.

Koulman Dzh., 2001. Kapital sotsialnyy i chelovecheskiy [Social and Human Capital]. Obshchestvennyye nauki i sovremennost [Social Sciences and Modernity], no. 3, pp. 122-139.

Kupreychenko A.B, 2008. Psikhologiya doveriya $i$ nedoveriya [Psychology of Trust and Distrust]. Moscow, Institut psikhologii RAN. 564 p.

Levada Yu.A., 2001. Mekhanizmy i funktsii obshchestvennogo doveriya [Mechanisms and Functions of Social Confidence]. Monitoring obshchestvennogo mneniya: ekonomicheskiye i sotsialnyye peremeny [Monitoring of Public Opinion: Economic and Social Changes], no. 3, pp. 7-13.

Lyasko A.K., 2004. Problema doveriya v sotsialnoekonomicheskoy teorii [The Problem of Trust in Socio-Economic Theory]. Moscow, Institut ekonomiki RAN. 189 p.

Maltseva A.P., Poliakov S.D., Semikasheva I.A., Silakova M.M., Eremina L.I., 2017. Sotsialnoye doveriye kak novoye napravleniye issledovaniy v pedagogike [Social Trust As a New Research Direction in Pedagogy]. Povolzhskiy pedagogicheskiy poisk [Volga Region Pedagogical Search], no. 1, pp. 38-44.

Takhanova O.V., Tsyrenova Ye.D., 2013. Institut doveriya $v$ sovremennoy ekonomike Rossii [Institution of Trust in the Modern Economy of Russia]. Ulan-Ude, Izd-vo VSGUTU. 180 p.
Trapkova A.V., 2004. Doveriye v rossiyskom malom i srednem biznese [Confidence in Russian Small and Middle Business]. Obshchestvennyye nauki $i$ sovremennost [Social Sciences and Contemporary World], no. 4, pp. 36-48.

Federalnyy zakon no. 122-FZ «O lekarstvennykh sredstvakh». Statya 44. Reklama lekarstvennykh sredstv [Federal Law No. 122-FZ “On Medicines”. Article 44. Advertising of Medicines]. URL: https:/ /legalacts.ru/doc/federalnyi-zakon-ot-22061998-n86-fz-o/.

Fukuyama F., 2004. Doveriye: sotsialnyye dobrodeteli i put $k$ protsvetaniyu [Trust: Social Virtues and the Path to Prosperity]. Moscow, AST Publ., Yermak Publ. 730 p.

Shamne N.L., Shishkina Ye.V., 2017. Nauchnopopulyarnyye meditsinskiye internet-izdaniya na nemetskom yazyke: strukturnyy i funktsionalnyy aspekty [German Popular Scientific Medical Online Media: Structural and Functional Aspects]. Vestnik Volgogradskogo gosudarstvennogo universiteta. Seriya 2. Yazykoznaniye [Science Journal of Volgograd State University. Linguistics], vol. 16, no. 2, pp. 143-151. DOI: https://doi.org/10.15688/jvolsu2.2017.2.15.

Shaposhnikova V.V., 2008. Institut doveriya kak nravstvennaya osnova sotsialnogo kapitala [Institution of Trust As the Moral Basis of Social Capital]. Vestnik Kostromskogo gosudarstvennogo tekhnologicheskogo universiteta [Bulletin of the Kostroma State Technological University], no. 18, pp. 16-19.

Frederiksen M., 2014. Relational Trust: Outline of a Bourdieusian Theory of Interpersonal Trust. Journal of Trust Research, no. 4 (2), pp. 167-192.

Larzelere R.E., Huston T.L., 1980. The Dyadic Trust Scale: Toward Understanding Interpersonal Trust in Close Relationships. Journal of Marriage and the Family, vol. 42, no. 3, pp. 595-604.

Levi M., Stoker L. 2000. Political Trust and Trustworthiness. Annual Review of Political Science, vol. 3, pp. 475-507.

Lewis J.D., Weigert A.J., 1985. Trust As a Social Reality. Social Forces, vol. 63, no. 4, pp. 967- 985.

Thom D.H., Kravitz R.L., Bell R. A., KrupatE., Azari R., 2002. Patient Trust in the Physician: Relationship to Patient Requests. Family Practice, vol. 19, no. 5, pp. 476-483.

Stolle D., 2002. Trusting Strangers: The Concept of Generalized Trust in Perspective. Österreichische Zeitschrift für Politikwissenschaft, Bd. 31, Nr. 4, S. 397-412. 


\section{МАТЕРИАЛЫ И СООБЩЕНИЯ}

\section{Information About the Authors}

Nikolay L. Shamne, Doctor of Sciences (Philology), Professor, Head of the Institute of Philology and Intercultural Communication, Volgograd State University, Prosp. Universitetsky, 100, 400062 Volgograd, Russia, nikolay.shamne@volsu.ru, https://orcid.org/0000-0002-5745-8907

Ekaterina V. Shishkina, Candidate of Sciences (Philology), Associate Professor, Department of Foreign Languages with a Course of Latin, Volgograd State Medical University, Pavshikh Bortsov Sq., 1, 400131 Volgograd, Russia, e.w.shishkina@gmail.com, https://orcid.org/0000-0001-8620-8387

\section{Информация об авторах}

Николай Леонидович Шамне, доктор филологических наук, профессор, директор института филологии и межкультурной коммуникации, Волгоградский государственный университет, просп. Университетский, 100, 400062 г. Волгоград, Россия, nikolay.shamne@volsu.ru, https://orcid.org/0000-0002-5745-8907

Екатерина Викторовна Шишкина, кандидат филологических наук, доцент кафедры иностранных языков с курсом латинского языка, Волгоградский государственный медицинский университет, пл. Павших Борцов, 1, 400131 г. Волгоград, Россия, e.w.shishkina@gmail.com, https://orcid.org/0000-0001-8620-8387 